\title{
SUNBEDS USE - TANNING PATTERN AND UV PROTECTIVE BEHAVIOUR OF ADULTS OF THE TURIEC REGION
}

\section{Dvorstiakova B, Jakusova V, Ulbrichtova R, Hudeckova H.}

Department of Public Health, Jessenius Faculty of Medicine in Martin, Comenius University in Bratislava, Slovak Republic

\begin{abstract}
A b s tract
Introduction: Recent worldwide researches dealing with artificial sources of ultraviolet radiation have noticed an increased incidence of skin cancer, conjunctivitis, or decreased immunity. Melanoma is the most serious disease that may be caused by sunbeds.

Goal: The main goal of the study was to coherently process public health issues of sunbeds and find out a level of information and attitude of adult population in the Turiec Region.

Material and method: In the II. half of 2016 we carried out a questionnaire survey

focused on information and attitude of adult population towards sunbeds and their negative effect on humans. The total sample consisted of 121 adult participants (74 females and 47 males) from the Turiec Region.

Results: The age range of participants was $36 \pm 6.5$ years and the age range of sunbed users was $31 \pm 4.8(\mathrm{x} \pm \mathrm{SD})$. From the total sample of 121 participants $34(28.1 \%)$ visit sunbed and $87(71.9 \%)$ do not. Sunbeds are visited more by women (85.3\%), but men (p 0.05) take longer sunbaths than women. Women (p 0.05) were more informed about their phototype than men. Only 51 (42.2\%) of participants were aware of their skin phototype and better informed were participants with higher education. From the survey only $13(38.2 \%)$ participants used the combination of protective sunglasses and sunscreens.

Conclusion: The results show that visitors of sunbeds had a higher level of information than non-visitors. A negative aspect is that the participants didn't know the phototype of their skin and didn't use all protective aids. Most participants said that information on sunbed are inadequate. From the public health view it is very important to focus on prevention, spread information about diseases influenced by artificial source of UV radiation, and educate the population.
\end{abstract}

Keywords: sunbeds, malignant melanoma, health protection, skin phototype

\section{INTRODUCTION}

Sunbathing, in the opinion of many people, is an ideal way to relax and improve mood. This occurs because UVR stimulates secretion of endorphins - known as „happiness hormones"- in human organism. Exposure to UV radiation also initiates the physiological process of skin tanning, which is associated with damage to epidermal cells (1). The most common reaction to the harmful effect of sunbathing is erythema or inflammatory reaction of the skin. The appearance of erythema depends not only on the radiation, but also on the skin phototype, the length of the sunbathing, and the body part (2). Sunbaths are responsible for approximately 400,000 non-melanoma and 10,000 melanoma skin cancers each year in the US, Asia, and Europe (3). Malignant melanoma is responsible for 48,000 deaths worldwide and 7,000 deaths in Slovakia every year (4).

Worldwide researches of artificial UV radiation recorded that the occurrence of melanoma doubled in recent years. The most vulnerable groups are adolescents and people under the age of 30 that have $75 \%$ higher incidence of skin cancer (5). The relation between the creation of non-melanoma and melanoma skin cancers and visiting of tanning beds was proved.

\footnotetext{
Address for correspondence:

Mgr. Barbora Dvorštiaková, Department of Public Health, Jessenius Faculty of Medicine in Martin, Malá Hora 4B, 03601 Martin, Slovak Republic;

e-mail: barbora.dvorstiakova@gmail.com; phone number: +421 911997032
} 
Research shows that worldwide about 35\% of adult population and 19\% of adolescents visit sunbeds. In 2009 International Agency for Research on Cancer (IARC) classified artificial ultraviolet radiation (UV) as carcinogenic to humans (6).

For this reason the World Health Organization (WHO) worldwide called on countries to legally ban entry to sunbeds for persons under the age of eighteen. In Europe there is such ban in Britain, Scotland, Belgium, Finland, France, Germany, Portugal, and Spain. At present there is no valid legislation in Slovakia prohibiting the admission to sunbeds for persons under the age of eighteen.

\section{METHODS}

The survey was carried out between August and November 2016 in the Turiec Region. The study population included 121 participants living in the Turiec Region. The average age of participants was $36 \pm 6.5$ years and the highest number of participants (58) was in the age group of 26-45 years. Of the total 121 participants 34 used sunbeds. The questionnaire was distributed to random residents of the Turiec Region. In addition, it was also available on social networks and forums. The samples were selected using a simple random sampling method. Participation in the questionnaire survey was voluntary and anonymous.

The questionnaire was designed by the authors of this study and it is composed of two sections. In the first section the authors collected socio-demographic data such as age, gender, residence, education, and occupation. The socio-demographic records of the studied population are depicted in Table 1 .

The second section of the questionnaire consisted of 16 closed questions with only one correct answer and one question with more than one correct answer. This part of the

Table 1 Socio-demographic data of participants of the survey

\begin{tabular}{|c|c|c|}
\hline Factor & $\mathrm{n}(121)$ & $\%$ \\
\hline \multicolumn{3}{|l|}{ Age } \\
\hline $\begin{array}{l}18-25 \\
26-45 \\
46-59 \\
\geq 60\end{array}$ & $\begin{array}{c}34 \\
58 \\
28 \\
1\end{array}$ & $\begin{array}{c}28.1 \\
47.9 \\
23.1 \\
0.9\end{array}$ \\
\hline \multicolumn{3}{|l|}{ Gender } \\
\hline $\begin{array}{l}\text { Females } \\
\text { Males }\end{array}$ & $\begin{array}{l}74 \\
47\end{array}$ & $\begin{array}{l}61.2 \\
38.8 \\
\end{array}$ \\
\hline \multicolumn{3}{|l|}{ Place of residence } \\
\hline $\begin{array}{l}\text { Urban } \\
\text { Rural }\end{array}$ & $\begin{array}{l}72 \\
49\end{array}$ & $\begin{array}{l}59.5 \\
40.5\end{array}$ \\
\hline \multicolumn{3}{|l|}{ Education } \\
\hline $\begin{array}{l}\text { Primary school } \\
\text { Secondary school } \\
\text { University }\end{array}$ & $\begin{array}{c}0 \\
75 \\
46\end{array}$ & $\begin{array}{c}0.0 \\
62.0 \\
38.0\end{array}$ \\
\hline \multicolumn{3}{|l|}{ Occupation } \\
\hline $\begin{array}{l}\text { Healthcare workers } \\
\text { Other }\end{array}$ & $\begin{array}{l}23 \\
98\end{array}$ & $\begin{array}{l}19.0 \\
81.0\end{array}$ \\
\hline
\end{tabular}


questionnaire was focused on knowledge and attitudes of the participants towards ultraviolet radiation, sunbeds, malignant melanoma, and skin phototypes. The return of questionnaires was $82.9 \%$.

We processed the data in the Microsoft Office Excel 2013. We used descriptive statistics to analyse the data and Chi-square test. The value $(\mathrm{p}<0.05)$ was considered as statistically significant. Quantitative variables were described using the absolute number (n) in per cent (\%).

\section{RESULTS}

Close to 65\% (78) of participants correctly answered that UVR is non ionizing radiation. Males (34, i.e. 72.3\%) more often knew "what is UVR" than females (45, i.e. 60.8\%). There is a statistically significant difference $(\mathrm{p}<0.05)$ between participants living in the city $(58$, i.e. $78.4 \%)$ and participants living in the village (12, i.e. $24.5 \%)$.

The question about use of sunbeds was answered as follows: according to occupation, more $(\mathrm{p}=0.0168)$ non-healthcare workers $(30.6 \%)$ than healthcare workers $(17.4 \%)$ used sunbeds. Of the total of 121 participants $34(28.1 \%)$ used sunbeds; $29(39.2 \%)$ of them were females and $5(10.6 \%)$ were males. Statistically significant difference between females and males was $p=0.0006$. There are no statistically significant differences between the group of participants living in city and village, between age groups, and between levels of education (Table 2).

Table 2 Socio-demographic characteristics of the studied population, by using sunbeds

\begin{tabular}{|c|c|c|c|c|c|c|}
\hline \multirow[t]{3}{*}{ Factor } & \multicolumn{2}{|l|}{$\mathbf{N}$} & \multicolumn{2}{|c|}{ Sunbeds } & \multicolumn{2}{|c|}{ p- Value $\left(\mathrm{chi}^{2}\right)$} \\
\hline & \multicolumn{3}{|c|}{ users } & \multicolumn{2}{|c|}{ non-users } & \multirow[b]{2}{*}{$\mathrm{p}\left(\mathrm{x}^{2}\right)$} \\
\hline & $\mathrm{n}(121)$ & $\mathbf{N}$ & $\%$ & $\mathbf{N}$ & $\%$ & \\
\hline \multicolumn{7}{|l|}{ Age } \\
\hline $18-25$ & 34 & 13 & 38.2 & 21 & 61.8 & \\
\hline $26-45$ & 58 & 16 & 27.6 & 42 & 72.4 & 1.8915 \\
\hline $46-59$ & 28 & 5 & 17.9 & 23 & 82.1 & \\
\hline$\geq 60$ & 1 & 0 & 0.0 & 1 & 100.0 & \\
\hline \multicolumn{7}{|l|}{ Gender } \\
\hline Females & 74 & 29 & 39.2 & 45 & 60.8 & \\
\hline Males & 47 & 5 & 10.6 & 42 & 89.4 & $0.0006^{* *}$ \\
\hline \multicolumn{7}{|l|}{ Place of residence } \\
\hline Rural & 49 & 14 & 28.6 & 35 & 71.4 & \\
\hline Urban & 72 & 20 & 27.8 & 52 & 72.2 & 0.9240 \\
\hline \multicolumn{7}{|l|}{ Education } \\
\hline Primary school & 0 & 0 & 0 & 0 & 0 & \\
\hline Secondary school & 75 & 20 & 26.7 & 55 & 73.3 & \\
\hline University & 46 & 14 & 30.4 & 32 & 69.6 & 0.6544 \\
\hline \multicolumn{7}{|l|}{ Occupation } \\
\hline Healthcare workers & 23 & 4 & 17.4 & 19 & 82.6 & \\
\hline Other & 98 & 30 & 30.6 & 68 & 69.4 & $0.0168^{*}$ \\
\hline
\end{tabular}

Notes: ${ }^{*} \mathrm{p}<0.05,{ }^{* *} \mathrm{p}<0.001$ 
Fifty-one of our participants (42.2\%) know their skin phototype and seventy (57.8\%) do not. A significant difference was recorded by gender $(p=0.008)$. More females $(54.0 \%)$ compared to males $(23.4 \%)$ knew their skin phototype. There exists a statistically significant difference $(p=0.0003)$ between users and non-users of sunbeds. Of the total 34 users of sunbeds $23(67.7 \%)$ knew their skin phototype and of the 87 non-users of sunbeds 28 (32.2\%) did not know their phototype (Fig. 1).

The survey found that only $47.1 \%$ of sunbed users were advised about the health risks from sunbathing and the use of protective aids. And only $38.2 \%$ of the participants use a combination of protective aids (cream and eyeglasses). $27.2 \%$ of the participants said that they had undesirable effects after a visit to the sunbeds.

$100 \%$

$80 \%$

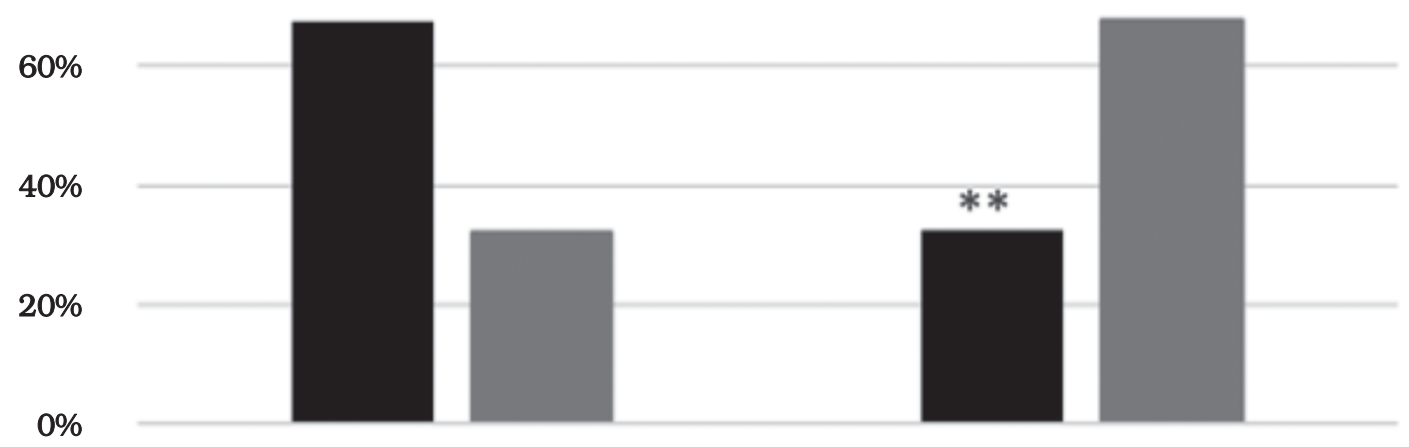

yes no

users of sunbeds non-users of sunbeds

Fig. 1 Percentages of users and non-users of sunbeds who knew and did not know their skin phototype, ${ }^{* *} \mathrm{p}<0.001$

\section{DISCUSSION}

Amounts of studies have investigated prevalence of sunbed use, knowledge and attitudes of sumbed users in other European countries. The issue of knowledge among young population regarding the risks resulting from excessive exposure to ultraviolet radiation, including the use of sunbeds, is extremely important. According to information provided by the WHO and IARC sunbeds are equally dangerous to human health as asbestos and tobacco. Research has shown a link between both melanoma and non-melanoma skin cancers and sun exposure or artificial UV radiation and that skin cancer may be preventable through the use of effective UV protection. According to the American Cancer Society the incidence of melanoma has increased progressively over the last 30 years. The worldwide documented increase of malignant melanoma's incidence by over 4\% per year stimulates an improvement of its diagnosis. In 2017 91,270 new cases have been diagnosed. For this reason we have ascertained the knowledge of the participants in the issue of malignant melanoma. The survey found that the participants were informed above the average. Our results were 
consistent with the results of Marušková et al. where nearly $75 \%$ of the participants knew about malignant melanoma (7).

When using sunbeds it is important to use protective aids such as glasses and sunscreens. The best UV protection is achieved by combination of both protective aids, however only $1 / 3$ of the participants used glasses and sunscreen at the same time. However, almost all the participants use at least glasses and around $20 \%$ of the participants did not use any protective aids. Similar results have been recorded by other European surveys that have addressed this issue $(8,9,10)$.

One of the factors that may influence the development of malignant melanoma is the phototype of the skin, so we surveyed the knowledge of the participants in this issue. Our findings are identical to the results of Torzewska et al. where it showed that only $1 / 2$ of the participants know what a skin phototype is (2). Several studies show that participants have a lack of knowledge of their phototype. Some studies indicate that only $16-32 \%$ of the participants know their skin phototype $(2,11)$. In our survey we found that $42 \%$ of the participants knew their skin phototype. Based on data of Jakušová, $2 / 3$ of the participants knew their skin phototype (12). The difference could be due to the fact that the survey was attended by medical students.

According to a recent review and meta-analysis including more than 490,000 participants and 88 studies from 16 countries established the international prevalence of over exposure to indoor tanning at $35.7 \%$ in adults with an average of $42 \%$ of the adult population in Europe using artificial UV radiation for sunbathing. Several publications have identified a typical sunbed user as a young woman, belonging to a higher socio-economic class, with a higher level of education and higher income $(8,9)$. These results have been partially confirmed in our survey where we found that sunbeds are used mainly by women 18-35 years old. However, our results showed that a typical sunbed user was a woman, living in the city, with a secondary education. These results have also been confirmed by Schneider et al. (9)

Some surveys show that most of the sunbed users exceed recommended exposure times and about $16 \%$ of sunbed users visit sunbeds 100 times per year (8). Our survey showed that $2 / 3$ of the participants used sunbeds 1-2 times a week and averaged 6-15 minutes. Schneider et al. indicate that the average sunbathing time was 13.6 minutes (9). Yearly the sunbeds were used by $2 / 3$ of the participants, it means that they combined artificial and natural UV radiation. These results were partly confirmed by the Tisoňová and Komárek surveys where approximately one-half of the participants visited sunbeds (13).

We found that only $1 / 2$ of the participants were aware of health risks and the use of protective aids. Our results were consistent with the results of Schneider et al. who found that $2 / 3$ of the participants were not aware of health risks and about $1 / 2$ about the need to use protective means (9).

The survey found that only $1 / 4$ of the participants had health problems after exposure to artificial UV radiation from sunbeds. The participants most often reported skin rashes and skin redness. The most common reasons for sunbathing were sunbathing, relaxation followed by holiday preparation, and treatment of atopic eczema. Similar reasons are given by Skonieczna et al. where participants most often visit sunbeds to increase attractiveness (14).

Knowledge and attitudes of individuals are vital targets for public education programs. However, there is still a lack of information among population considering the safety of sunbeds use $(11,12)$. Schneider et al. reported alarmingly poor quality of services provided by tanning salons (9). In our study the participants have reported that there is little information in Slovakia about the undesirable effects caused by sunbeds and the lack of awareness of this issue. The participants reported that the most frequent sources of information about sunbeds were the Internet and women's magazines. Similar data about sunbeds and knowledge and attitudes were reported by other studies, too. $(14,2)$. In order to reduce the incidence of skin cancers, as well as diminish the scale of other negative consequences of 
excessive UV exposure of the skin, we should consider introducing a ban on use of tanning salons by persons under 18 years of age. Slovakia does not have legislation that would regulate this issue.

\section{CONCLUSION}

Our survey extends the understanding of skin health habits. The issue of sunbeds is currently an actual public health problem. The results of our survey were positive because they pointed to lower sunbathing rates than the European average. However, heretofore lack of data on sunbed use prevail in the general Slovak population. Young women used sunbeds more often than men and women were better informed about negative effects of sunbeds. There was also a positive finding that almost all sunbed users used protective glasses. However, only a small part of them used a combination of protective glasses and sunscreen. It was alarming to find out that the participants did not know what skin phototype means and, therefore, could not even determine their phototype. Based on the results of the survey we believe that the issue of sunbeds should be given a greater emphasis and should be included in preventive programs in Slovakia.

\section{REFERENCES}

1. Cui R, Widlund HR, Feige E, Lin JY, Wilensky DL, Igras VE, D'Orazio J, Fung CY, Schanbacher CF, Granter SR, Fisher DE. Central Role of p53 in the Suntan Response and Pathologic Hyperpigmentation. Cell, 2006; 128(5):853-864

2. Torzewska K, Malinowska-Borowska J, Wypych-Ślusarska A, Zieliński G. Tanning in solarium knowledge, attitudes and Polish habits. Medycyna Środowiskowa - Environmental Medicine, 2014; 17(1):52-59

3. Wehner MR, Chren M, Nameth D, Choudhry A, Gaskins M, Nead KT, Boscardin WJ, Linos E. International prevalence of indoor tanning a systematic review and meta-analysis. JAMA Dermatol, 2014; 150(4):390-400

4. Hegyi J. Malignant melanoma in Slovakia. False alarm or a dangerous issue? [Internet]. Bratislava: Department of Dermatovenerology LFUK; 2013 [cited 2018 August 05] Available from: http://verejnezdravotnictvo.szu.sk/SK/2013/4/Hegyi.pdf

5. World Health Organization, International Agency for Research on Cancer. Exposure to artificial UV radiation and skin cancer. Fact sheet Number 287 [Internet]. Lyon; 2005 [cited 2018 July 19]. Available from: http://www.iarc.fr/en/publications/pdfsonline/wrk/wrk1/ArtificialUVRad\&SkinCancer.pdf

6. American Cancer Society. Cancer Facts and Figs [Internet]. Atlanta; 2014 [cited 2018 July 30] Available from: https://www.cancer.org/content/dam/cancer-org/research/cancer-facts-andstatistics/annual-cancer-facts-and-figures/2014/cancer-facts-and-figures-2014.pdf

7. Marušková L, Pekarčíková J, Černušková Z. Informing the visitors of the solariums about skin tumors and prevention options [Internet]. Trnava: Department of Public Health; 2008 [cited 2018 August 03] Available from: http://verejnezdravotnictvo.szu.sk/SK/2008/2008-4/maruskova.htm

8. Grange F, Mortier L, Crine A, Robert C, Sassolas B, Lebbe C, Lhomel C, Saiag P. Prevalence of sunbed use, and characteristics and knowledge of sunbed users: Results from the French population-based edifice melanoma survey. JEADV, 2015; 29(2):23-30

9. Schneider S, Zimmermann S, Diehl K, Breitbart EW, Greinert R. Sunbed use in German adults: Risk awareness does not correlate with behaviour. ADV, 2009; 89(5):470-475

10. Ezzedine K, Malvy D., Mauger E, Nageotte O, Galan P, Hercberg S, Guinot C. Artificial and natural ultraviolet radiation exposure: Beliefs and behaviour of 7200 French adults. JEADV, 2008; 22(2):186-194

11. Haluza D, Simic S, Moshammer H. Sunbed use prevalence and associated skin health habits: results of a representative, population-based survey among austrian residents. International Journal of Environmental Research and Public Health, 2016; 13(2):231 
12. Jakušová V. Ultraviolet radiation and mobile communications. Physical properties, biological effects and health protection. Bratislava: Samosato; 2009. (in Slovak)

13. Tisoňová V, Komárek K. Information and attitudes of future health workers to sunbeds and solar studies [Internet]. Ružomberok: Department of Public Health; 2009 [cited 2018 July 25] Available from: https://zdravi.euro.cz/clanek/sestra/informovanost-a-postoje-budoucich-zdravotnickychpracovniku-k-so-447337

14. Skonieczna J, Olejniczak D, Zakrzewska K, Duda-Zalewska A, Bodych A, Kitowska W, Cieślak I, Kielan A, Smoleńska E, Makaruk J, Lech-Wróblewska A, Jabłońska M, Fydryk D, Korczyńska M, Izdebski R, Zalewska M, Koczkodaj P, Gawińska E. Assessment of knowledge about the effects of uv radiation on health and health behaviors associated with sunbathing in gymnasium students. Przegl Epidemiol, 2016; 70:65-72

Received: August, 16,2018

Accepted: October,8,2018 